\title{
Revision of the Neotropical genus Mulfordia Malloch (Diptera, Muscidae)
}

\author{
Márcia Souto Couri \& Juliana Morgado Fernandes
}

Departamento de Entomologia, Museu Nacional, Universidade Federal do Rio de Janeiro, Caixa Postal 20940-040, Quinta da Boa Vista, São Cristóvão, Rio de Janeiro-RJ, Brasil. courimarcia@gmail.com; jumorgado89@gmail.com

\begin{abstract}
Revision of the Neotropical genus Mulfordia Malloch (Diptera, Muscidae). The present paper provides a revision of Mulfordia Malloch (Diptera, Muscidae), including redescriptions of the genus and of its three species. The descriptions are complemented with illustrations of some characters to make the recognition of the species easier and to help the use of the key. The male terminalia of $M$. ferruginea Malloch is described for the first time.
\end{abstract}

KEYWORDS. Insecta; morphology; Neotropical; taxonomy.

The genus Mulfordia (Diptera, Muscidae) was described by Malloch (1928) based on one female of Mulfordia ferruginea from Bolivia. The genus now includes three species, M. ferruginea Malloch, 1928, M. longipes (Stein, 1911) and M. secunda Snyder, 1951. Mulfordia longipes was originally described by Stein (1911) in Mydaea and posteriorly transferred to Mulfordia by Pont (1972).

The genus is little known and very poorly represented in collections (practically only the type material). After the original descriptions of the species, no other paper treated them, except catalogues (Séguy 1937; Pont 1972; Carvalho et al. 1993, 2005), keys to identification (Couri \& de Carvalho 2002) and a short reference to the type specimen of $M$. ferruginea (Carvalho 1980). The distribution of the species of the genus is limited to the Neotropical region and, according to the present knowledge, is restricted to Bolivia and Peru.

Species of Mulfordia can be recognized by the absence of prealar seta, dorsocentrals $2+3$, suprasquamal ridge setulose, katepisternals $1+2$, posterior spiracle triangular and with a few black hairs on center, hind coxa setulose on posterior surface and $\mathrm{R}_{4+5}$ with few short ventral setulae at base. The genus was originally positioned among the Phaoninae, but in the current classification of Muscidae (Carvalho et al. 2005), it is positioned within the subfamily Cyrtoneurininae.

This paper aims to provide a revision of the three species included in Mulfordia, including redescriptions of the genus and of the species and a key to their identification. Complete redescriptions are presented, except for the terminalia of $M$. longipes and $M$. secunda as the dissections were not allowed by the curators of the museums where the material is deposited, due to the scarcity of specimens in the collections. Only the terminalia of the type-species, M. ferruginea, was dissected, described and illustrated.

\section{MATERIAL AND METHODS}

The holotypes of $M$. ferruginea and M. longipes, deposited respectively at National Museum of Natural History
(USNM) and Staatliches Museum für Tierkunde (SMT), were directly examined. The redescription of the holotype of $M$. secunda was based on photos gently sent by the Diptera curator and by the photographer of the American Museum of Natural History (AMNH), where the type is deposited. Personal notes of Dr. Dalci Albuquerque on the holotype were also used. The terminology followed McAlpine et al. (1981) and Stuckenberg (1999) for postpedicel. Colour images were taken with a stereomicroscope Leica MZ16 and assembled using Syncroscopy Auto-Montage.

\section{Mulfordia Malloch, 1928}

Mulfordia Malloch, 1928: 467. Type-species: Mulfordia ferruginea Malloch, 1928 (orig. des.). Refs.: Séguy 1937: 279 (cat.); Pont 1972: 48 (cat.); Carvalho et al. 1993: 56 (cat.); Couri \& de Carvalho 2002: 149 (key to species) and Carvalho et al. 2005: 92 (cat.)

Diagnosis. Male holoptic (M. longipes) or dichoptic ( $M$. ferruginea). Arista plumose; prosternum bare; prealar absent; dorsocentrals 2+3; scutellum with cilia on margins; anepimeron with 1-3 short fine hairs on upper margin; suprasquamal ridge with fine cilia close to base; katepisternals $1+2$, posterior spiracle triangular and with a few black hairs on center, meron with fine discal setulae; hind coxa haired on posterior surface; calcar absent; vein $\mathrm{M}_{1+2}$ slightly curved at the apex to $\mathrm{R}_{4+5}$ in $M$. ferruginea and straight in $M$. longipes and $M$. secunda, $\mathrm{R}_{4+5}$ with few short ventral setulae near base (Fig. 1). Sternite 1 haired. Male terminalia as in Figs 2-7 (based on the holotype of M. ferruginea).

Discussion. Mulfordia was added to the cladistic analysis of Couri \& Carvalho (2003). The analysis positioned Mulfordia among the Cyrtoneurininae (as Dichaetomyiinae in the paper) confirming its position among the subfamilies of Muscidae.

Note. In Carvalho \& Couri (2002) key to Muscidae genera, Mulfordia runs to couplet 21. With the examination of the type material, we corrected the disposition of the katepisternals to $1+2$, so, it is necessary to make the follow- 
ing correction in the key to correctly reach the genus Mulfordia.

21. Suprasquamal ridge setulose or with only few fine cilia near base 22

- Suprasquamal ridge bare 23

22. Dorsocentral setae 2:3; prosternum bare

Mulfordia Malloch [Part II, page 149]

- Dorsocentral setae 2:4; prosternum setulose Scutellomusca Townsend [Part II, page 172]

\section{Key to species}

1. General colour yellow ferrugineous; acrostichals $0: 1$; wing veins $\mathrm{R}_{4+5}$ and $\mathrm{M}$ slightly convergent at apex

M. ferruginea Malloch

1 '. General colour brown with grey pollinosity; acrostichals 0:0; wing veins $\mathrm{R}_{4+5}$ and $\mathrm{M}$ parallel at apex

2. Wing infuscated; legs brown M. longipes (Stein)

2'. Wing clear; legs with femora and tibia light brown ........ M. secunda Snyder

\section{Mulfordia ferruginea Malloch, 1928}

(Figs 1-12)

Mulfordia ferruginea Malloch, 1928: 467. Holotype male (not gynandromorph as in Carvalho et al. 2005), USNM. Type-locality: Bolivia, Tumupasa. Distr.- Bolivia.

Mulfordia ferruginea; Séguy 1937: 279 (cat.); Pont 1972: 48 (cat.); Carvalho 1980: 57 (short reference on the possibly gynandromorph type); Carvalho et al. 1993: 56 (cat.); Couri \& Carvalho 2002: 149 (key to species); Carvalho et al. 2005: 92 (cat.).

Length. body: $7.8 \mathrm{~mm}$; wing: $7.2 \mathrm{~mm}$.

General coloration. Yellow ferrugineous. Head with frons dark brown and lunule slightly reddish; parafacial, frontoorbital plate and gena yellow ferrugineous, with a slightly grey pollinosity; postpedicel yellow ferrugineous and arista yellow; palpus dark brown; notum with traces of four brown vittae on prescuttum and with a silver pollinosity close to head, under certain lights; pleurae brown. Anterior spiracle brownish yellow. Halter, calypters and wing yellowish. Legs with femora and tibia yellow; tarsi brown. Abdomen yellow ferrugineous with no marks.

Head. (Fig. 8 and 9) Dichoptic; eyes with very few hairs, 6 pairs of fronto-orbital setae, the basal stronger, the median ones fine and the upper one long, back and outwards directed; ocellar seta very long; antenna inserted a little below middle of eyes, postpedicel about 3.2 times the length of the pedicel; arista with long plumae. Vibrissa strong, longer than the length of arista; palpus shor and filiform; proboscis strong, labellum well developed.

Thorax. (Figs 11 and 12). Acrostichals 0:1; dorsocentrals $2+3$ the first one about half of the length of the other; 1 postpronotal; 2 presuturals; 2 intra-alars; 2 supra-alars; notopleuron with 2 setae, scutellum with one short basal pair and a long sub-basal and apical pairs of setae; anterior spiracle elongated; anepisternum with ground cilia and a series of six long setae on the posterior edge; katepisternals 1:2 with the postero-superior seta longer than the others; posterior spiracle triangular. Wing with vein $\mathrm{R}_{4+5}$ and $\mathrm{M}$ slightly convergent at apex. Vein $\mathrm{R}_{4+5}$ with short cilia at base. Legs with fore femur with a row of posterodorsal, dorsal and posteroventral setae; fore tibia with one median anterodorsal seta; apical setae on posterodorsal, posteroventral, dorsal and ventral surfaces; claws and pulvilli short. Mid femur with one median and one preapical anterodorsal setae; ventral surface with two long setae on basal third; posterior surface with two pre-apical setae and dorsal surface with one pre-apical; mid tibia with two posterior setae inserted on the limits of the thirds; all surfaces with apical setae, the ventral one longer than the others. Hind femur with a complete anterodorsal row of setae, stronger on apical forth; anteroventral surface with a row of setae more developed on apical third; hind tibia with two anteroventral setae on middle third and one median anterodorsal; dorsal, ventral and anteroventral surfaces with an apical setae.

Abdomen. (Fig. 10). Long, tergites 1+2-4 with one strong lateral pair of setae; tergites 4 and 5 with one median pair of setae. Sternite 1 setulose. Sternite 5 high, almost three times higher than wider (Fig. 2); sternite 6 asymmetric, only with left arm developed (Figs 3 and 5).

Terminalia. Cercal plate longer than wide in dorsal view (Fig. 4); epandrium, cercal plate, surstilus and sternite 6 as in Fig. 5; phallic complex as in Figs 6 and 7.

Material examined. Holotype. Tumupasa/Bolivia Dec/W. M. Mann. Mulford Biol. Expl./1921-1922./Type N [no number]/USNM [red label]. Mulfordia ferruginea Type/Det. J. R. Malloch.

Discussion. Malloch (1928) described the species based in one female from Bolivia (Tumupasa), collected by the Mulford Biological Expedition. Dr. Dalci Albuquerque in his personal notes on the type mentioned that it was a male and not a female and that Malloch could have been confused by the dichoptic condition of the head of the specimen. Albuquerque also called attention to the different aspect of the male terminalia and that the specimen could be a gynandromorph. The dissection the specimen terminalia confirmed that the holotype is a male.

\section{Mulfordia longipes (Stein, 1911)}

(Figs 13-16)

Mulfordia longipes Stein, 1911: 80 (Mydaea). Holotype male, SMT. Typelocality: Bolivia, Lorenzopata. Distr.- Bolivia.

Mydaea longipes; Stein 1919: 120 (cat.); Séguy 1937: 287 (cat.).

Mulfordia ? longipes; Pont 1972: 48 (cat.; new combination); Carvalho et al. 1993: 56 (cat.).

Mulfordia longipes; Pont 2001: 476 (notes on type); Couri \& de Carvalho 2002: 149 (key to species); Carvalho et al. 2005: 92 (cat.).

Length. body: $8 \mathrm{~mm}$; wing: $7.4 \mathrm{~mm}$.

General coloration (Fig. 13). Brown with grey pollinosity. Head with frons brown, lunule, parafacial, fronto-orbital plate 


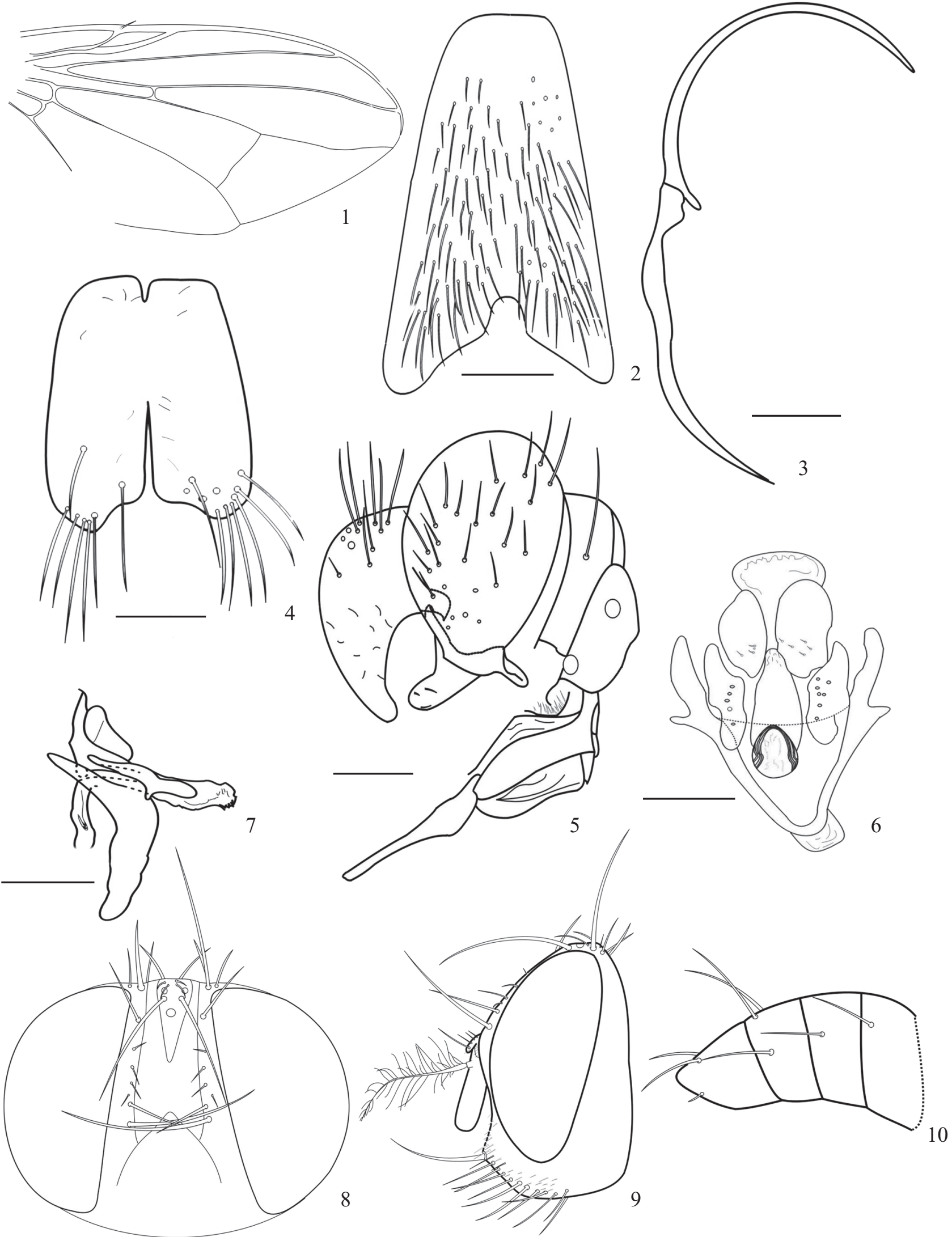

Figs. 1-10. Mulfordia ferruginea Malloch, male: 1. wing, ventral view; 2. sternite 5, dorsal view; 3. sternite 6, dorsal view; 4. cercal plate, dorsal view; 5. epandrium, cercal plate, surstyli and sternite 6 , right lateral view; 6. phallic complex, dorsal view; 7. phallic complex, lateral view; 8 . head, frontal view; 9. head, lateral view; 10. abdomen, lateral view. Scale bars: $0.1 \mathrm{~mm}$. 
and gena brown, grey pollinose; antenna and arista dark brown; palpus dark brown; notum, with traces of four brown vittae on prescuttum; pleurae brown with grey pollinosity. Anterior spiracle brown. Calypters whitish with margins light brown. Wing brown smoky, especially on apical longitudinal third. Legs brown. Abdomen brown, grey pollinose.

Head. Holoptic; eyes with short and sparse hairs, 5 pairs of fronto-orbital setae, all close to lunule, the basal stronger; ocelar setae very long; antenna inserted on middle of eyes, postpedicel about 3.2 times the length of the pedicel; arista with long plumae. Vibrissa strong, longer than the length of arista; palpus short, filiform.

Thorax (Fig. 14). Acrostichals indistinct; dorsocentrais $2+3$; 1 postpronotal long; 2 presuturals; 2 intra-alars; 2 supra-alars; notopleuron with 2 setae, scutellum with one long basal and one long apical pairs of setae; anterior spiracle elongated; anepisternum with a series of five setae on the posterior edge, one of them shorter than the others; katepisternals 1:2 with the postero-superior seta longer than the others; posterior spiracle triangular. Wing with $\mathrm{R}_{4+5}$ and M parallel at apex (Fig. 15). Legs with fore femur with a row of posterodorsal, dorsal and posteroventral setae; fore tibia with one supra median anterodorsal seta; apical setae on posterodorsal, posteroventral, dorsal and ventral surfaces; claws and pulvilli short. Mid legs broken. Hind femur with complete anterodorsal and anteroventral rows of setae; hind tibia with one anterodorsal median and two anteroventral inserted on the limits of the thirds; preapical anterodorsal and anteroventral and a long anterior apical seta.

Abdomen. Long, tergites 1+2-4 with one strong lateral pair of setae; tergites 4 and 5 with one median pair of setae. Sternite 1 setulose.

Material examined. Holotype male, SMT: Bolivia-Mapiri/2000m. 6.v.03/Lorenzopata. Coll. W. Schnuse/1911-3. Mydaea/longipes/sp. nov. [Stein's label]. Holotype/Mulfordia/longipes/Stein, 1911/Conf. A. C. Pont 1999 (Fig. 16).

Discussion. Pont (2001) examined the type during the re-curation of the families Fanniidae and Muscidae in the SMT collection and confirmed the transference of the species to Mulfordia.

\section{Mulfordia secunda Snyder, 1951}

(Figs 17-20)

Mulfordia secunda Snyder, 1951: 4. Holotype female, AMNH. Type-locality: Peru, Junín, Chanchamayo. Distr.-Peru. Refs.: Pont 1972: 48 (cat.); Carvalho et al. 1993: 57 (cat.); Couri \& de Carvalho 2002: 149 (key to species) and Carvalho et al. 2005: 92 (cat.).

Length. Female: body: $8-9 \mathrm{~mm}$.

General coloration. (Fig. 17). Brown with gray pollinosity. Head with frons face, parafacial, fronto-orbital plate and gena brown; antenna with apex of pedicel and base of postpedicel brown, flagellomere dark brown pollinose and arista light brown; proboscis and palpus dark brown; mesonotum, presuturally, bluish-black, grey pollinose with traces of four dark vittae; pleura brown. Anterior spiracle light brown. Halter yellow; calypters white; wing hyaline. Legs with femora and tibia light brown; tarsi brown. Abdomen grey with no marks.

Head (Fig. 18). Dichoptic; eyes with very few hairs, six pairs of fronto orbital seta, the basal and the apical ones stronger, the median ones fine and the upper one long and outwards directed; antenna inserted below middle of eyes; antenna with postpedicel about 3.2 times length of the pedicel; arista with long plumae. Vibrissa strong, longer than the length of arista; palpus filiform.

Thorax (Fig. 19). acrostichals 0:0; dorsocentrals 2+3; 1 postpronotal; 2 intra-alars; prealar absent; 2 supra-alars; notopleuron with 2 setae; scutellum with one long basal pair and short sub-basal and apical pairs of setae; anterior spiracle elongated prosternum bare; three proepisternals; anepisternum with ground cilia and a series of four setae on the posterior edge; katepisternals 1:2 with the postero-superior seta longer than the others; posterior spiracle triangular. Wing with vein $\mathrm{R}_{4+5}$ and $\mathrm{M}$ parallel at apex (Fig. 20). Legs with fore femur with a row of posterodorsal, dorsal and posteroventral; fore tibiae with a median anterodorsal setae; claws and pulvilli short. Mid femur on ventral surface with two long setae on basal third; posterior surface with three pre-apical setae; mid tibia with two anterodorsal setae; dorsal and ventral surfaces with apical seta, the last one longer than the others. Hind femur with one strong and one weak sub-apical anteroventral setae, the base of anteroventral and posteroventral surfaces with a few basal hairs; hind tibiae with one anterodorsal and two anteroventral median setae.

Abdomen. Lanceolate, tergites $1+2$ with one strong lateral pair of setae; tergites 3 with a row of about six longs apicals setae and tergites 4 with a row of four apicals setae. Sternite 1 setulose.

Material examined (type specimen examined only through photographs). Holotype female, AMNH: Chanchamayo/Department of Junin/ Peru/May 18, 1948 (José M. Schunk).

Discussion. The type series also includes seven female paratypes. Snyder (1951) placed this species in Mulfordia with some hesitation, as it differs from the type-species, $M$. ferruginea, in not having the fourth vein slightly curved forward at apex and in having two pairs of posterior parafrontal bristles, instead of one. But the presence of the setulose hairs on the hind coxae above and on the suprasquamal ridge were sufficient, according to him to place it in Mulfordia.

\section{ACKNOWLEDGMENTS}

The authors are grateful to the curators of the collections Dr. David Grimaldi, Dr. Alexander Riedel and Dr. Raymond Gagné for having gently loaned the material and Stephen Thurston (AMNH) for sending the photos of the holotype of M. secunda. 

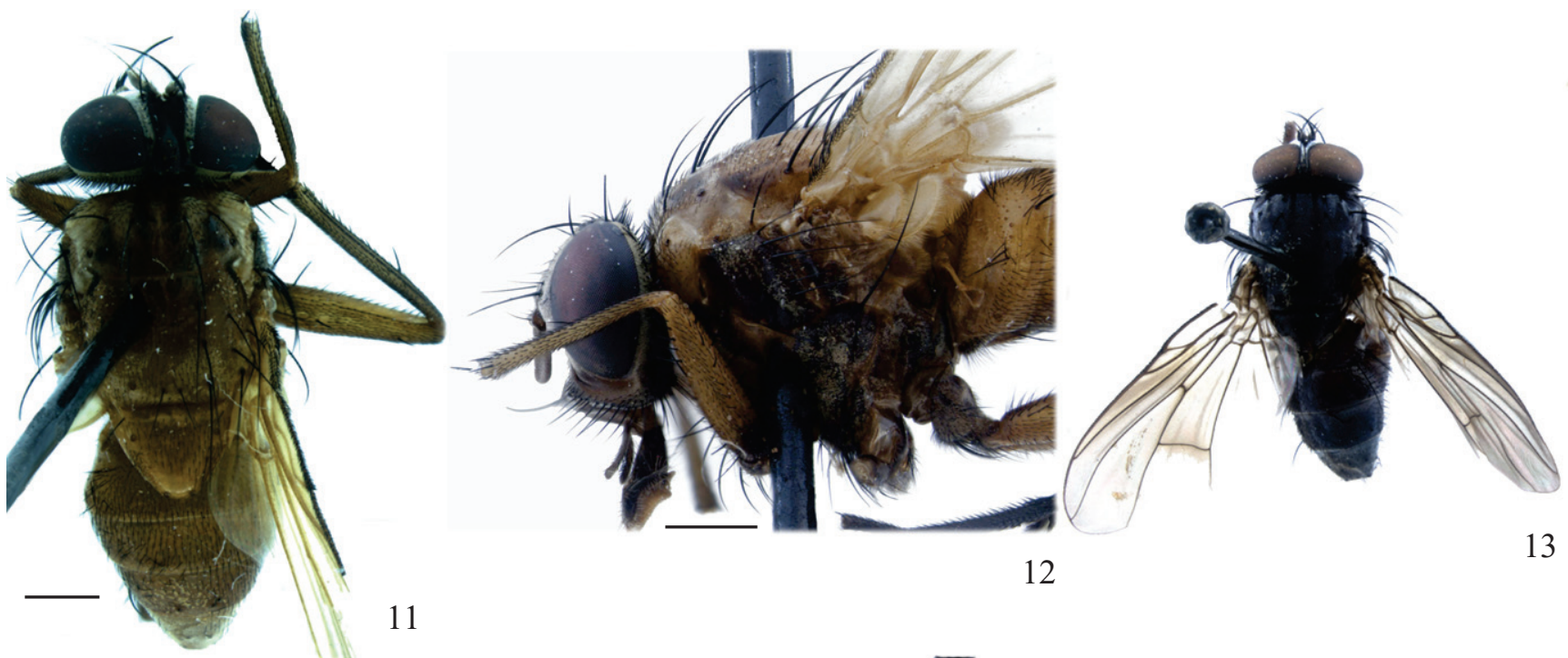

11

12
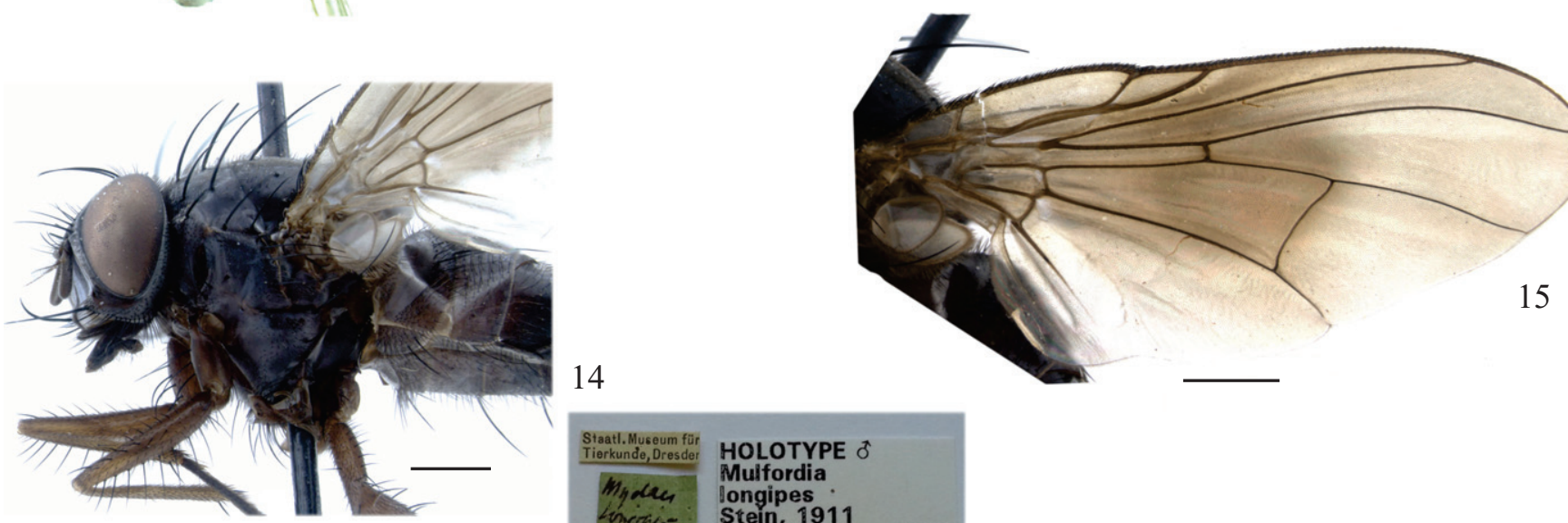

14
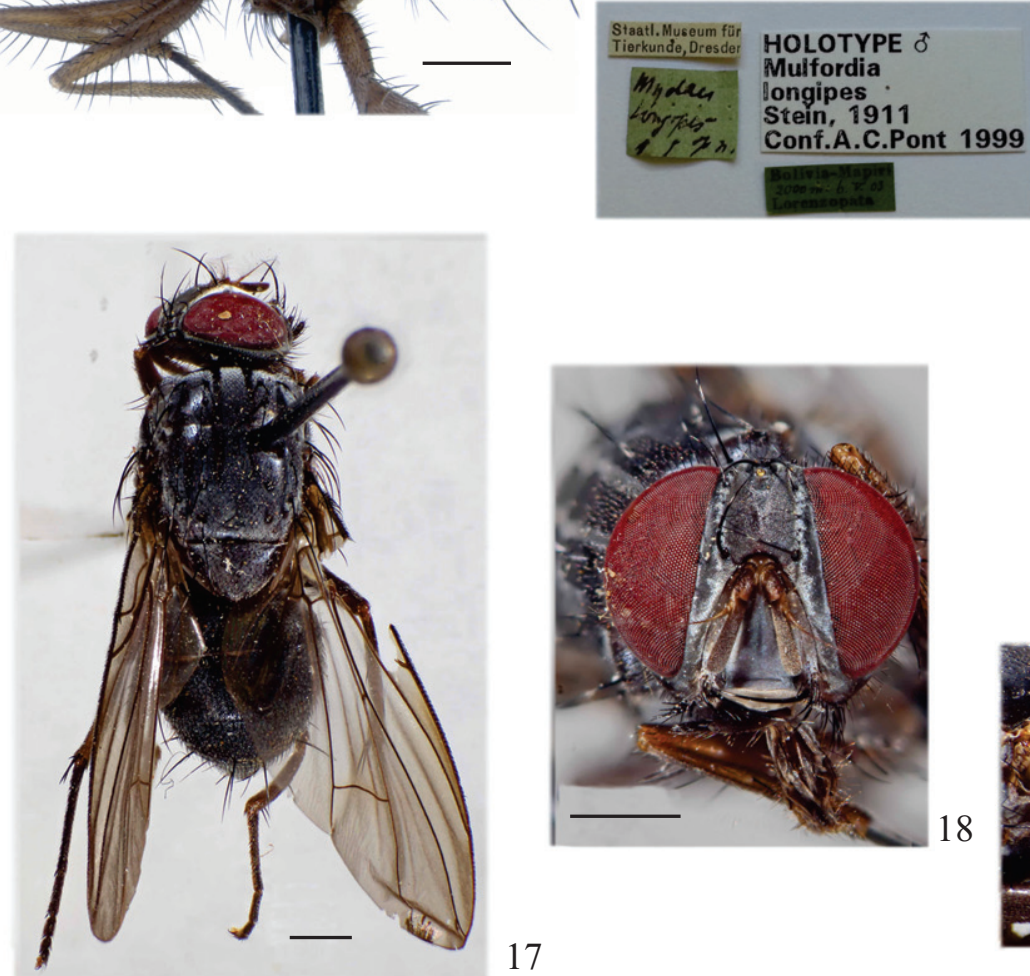

16

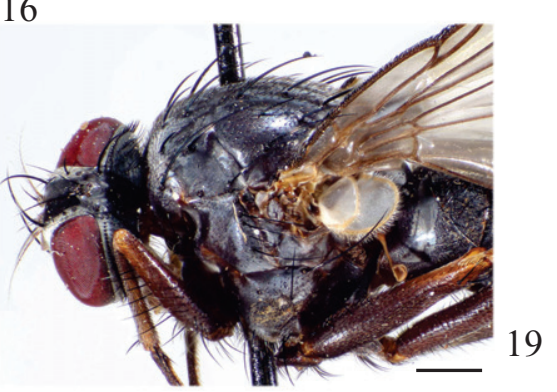

17

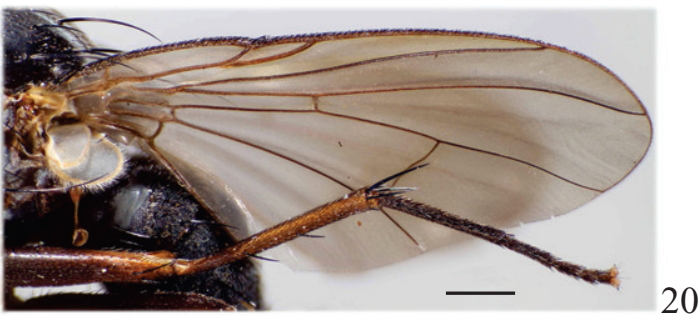

Figs. 11-21. 11. Mulfordia ferruginea Malloch, male, dorsal lateral view; 12. Mulfordia ferruginea Malloch, male, thorax, lateral view; 13. Mulfordia longipes (Stein), male, dorsal view; 14. Mulfordia longipes (Stein), male, thorax, lateral view; 15. Mulfordia longipes (Stein), male, wing, lateral view; 16. Mulfordia longipes Malloch, holotype labels; 17. Mulfordia secunda Snyder, female, dorsal, view; 18. Mulfordia secunda Snyder, female, head, frontal view; 19. Mulfordia secunda Snyder, female, thorax, lateral view; 20. Mulfordia secunda Snyder, female, wing. Scale bars: $1.0 \mathrm{~mm}$. 


\section{REFERENCES}

Carvalho, C.J.B. 1980. Estudo sobre Charadrella Wulp, 1896 (Diptera, Muscidae, Cyrtoneurininae). Dusenia 12: 57-62.

Carvalho, C.J.B \& Couri, M.S. 2002 Part I. Basal groups, p.17-132. In: Carvalho, C.J.B. (ed.). Muscidae (Diptera) of the Neotropical Region: taxonomy. Curitiba, Editora Universidade Federal do Paraná, $287 \mathrm{p}$.

Carvalho, C.J.B., Couri, M.S., Pont, A.C., Pamplona, D. \& Lopes, S.M. 1993. Part II. Muscidae, p.1-201. In: Carvalho, C.J.B. (ed.). A catalogue de the Fanniidae and Muscidae of the Neotropical region. Curitiba, Sociedade Brasileira de Entomologia, 230 p.

Carvalho, C.J.B., Couri, M.S., Pont, A.C., Pamplona, D. \& Lopes, S.M. 2005. A Catalogue of the Muscidae (Diptera) of the Neotropical Region. Zootaxa 860: 1-282.

Couri, M.S. \& Carvalho, C.J.B. 2002. Part II. Apical groups, p.133-287. In: Carvalho, C.J.B. (ed.) Muscidae (Diptera) of the Neotropical Region: taxonomy. Curitiba, Editora Universidade Federal do Paraná, $287 \mathrm{p}$

Couri, M.S. \& Carvalho, C.J.B. 2003. Systematic relations among Philornis Meinert, Passeromyia Rodhain \& Villeneuve and allied genera (Diptera, Muscidae). Brazilian Journal of Biology 63: 223-232.
Malloch, J.R. 1928. Exotic Muscaridae (Diptera). XXI. Annals and Magazine of Natural History, Series 10, 1: 465-494.

McAlpine, J.F., Peterson, B.V., Shewell, G.E., Teskey, H.J., Vockeroth, J.R. \& Wood, D.M. (eds.) 1981. Manual of Nearctic Diptera. Vol. 1. Ottawa, Research Branch Agriculture Canada, monograph 27.

Pont, A.C. 1972. Family Muscidae, p.1-111. In: A Catalogue of the Diptera of the Americas South of the United States. São Paulo, Museu de Zoologia, Universidade de São Paulo, 97, 111 p.

Pont, A.C. 2001. The type-material of Diptera in the Staatliches Museum für Tierkunde, Dresden (Insecta). Part IV: Fanniidae and Muscidae. Entomologische Abhandlungen 59: 455-492.

Séguy, E. 1937. Diptera Fam. Muscidae. In: Wytsman, P. (ed.). Genera Insectorum, vol. 205. Brussels, Desmet-Verteneuil, 604 p.

Snyder, F.M. 1951. New Neotropical Muscidae (Diptera). American Museum Novitates 1494: 1-11.

Stein, P. 1911. Die von Schnuse in Südamerika gefangenen Anthomyiden. Archiv für Naturgeschichte 77: 61-189.

Stein, P. 1919. Die Anthomyidengattungen der Welt, analytisch bearbeitet, nebst einem kritisch-systematischen Verzeichnis aller außereuropäischen Arten. Archiv für Naturgeschichte A 83: 85-178.

Stuckenberg, B.R. 1999. Antennal evolution in the Brachycera (Diptera), with a reassessment of terminology relating to the flagellum. Studia Dipterologica 6: 33-48. 